\title{
Factors associated with acquisition of carbapenem-resistant Enterobacteriaceae ${ }^{1}$
}

\author{
Lilian Silva Lavagnoli² \\ Bil Randerson Bassetti ${ }^{3}$ \\ Thais Dias Lemos Kaiser ${ }^{2}$ \\ Kátia Maria Kutz ${ }^{4}$ \\ Crispim Cerutti Junior ${ }^{5}$
}

\begin{abstract}
Objective: to identify possible risk factors for acquisition of Enterobacterial strains with a marker for resistance to carbapenems. Methods: exploratory case-control study performed in hospital settings. The study sample consisted of patients with biological specimens that tested positive for carbapenem-resistant Enterobacteriaceae (cases), with the disk diffusion test and Etest, and controls with biological samples testing negative for carbapenem-resistant Enterobacteriaceae. In all, 65 patients were included: 13 (20\%) cases and 52 (80\%) controls. Results: the microorganisms isolated were Serratia marcescens (6), Klebsiella pneumoniae (4), and Enterobacter cloacae (3). Univariate analysis revealed that length of hospitalization prior to sample collection $(p=0.002)$ and having a surgical procedure $(p=0.006)$ were statistically significant. In the multivariable logistic regression model, both were still significant, with odds ratios of 0.93 ( $p=0.009 ; 95 \%$ CI: 0.89 to 0.98 ) for length of hospitalization prior to sample collection, and 9.28 ( $p=0.05 ; 95 \%$ $\mathrm{CI}: 1.01$ to 85.14 ) for having a surgical procedure. Conclusion: shorter hospitalization times and increased surveillance of patients undergoing surgery could play a decisive role in reducing the spread of carbapenem-resistant microorganisms in hospital settings.
\end{abstract}

Descriptors: Enterobacteriaceae; Drug Resistance, Microbial; Risk Factors; Epidemiology; Dissemination of Resistance; Hospital Environment.

\footnotetext{
${ }_{1}$ Paper extracted from Master's Thesis "Enterobactérias resistentes aos carbapenêmicos em dois hospitais da área metropolitana de Vitória-ES e seus fatores associados", presented to Universidade Federal do Espírito Santo, Vitória, ES, Brazil.

2 MSc, Microbiologist, Laboratório de Microbiologia Médica, Secretaria de Saúde, Vitória, ES, Brazil.

3 Physician, Hospital Estadual Central, Vitória, ES, Brazil. Physician, Hospital Santa Casa de Misericóridia de Vitória, Vitória, ES, Brazil.

${ }^{4}$ Specialist in Applied Microbiology, Microbiologist, Hospital Santa Casa de Misericóridia de Vitória, Vitória, ES, Brazil.

${ }^{5} \mathrm{PhD}$, Associate Professor, Universidade Federal do Espírito Santo, Vitória, ES, Brazil.
}

\section{How to cite this article}

Lavagnoli SL, Bassetti BR, Kaiser TDL, Kutz KM, Cerutti C Jr. Factors associated with acquisition of carbapenemresistant Enterobacteriaceae. Rev. Latino-Am. Enfermagem. 2017;25:e2935. [Access † __ _ ]; Available in: $\left.\right|_{\text {URL }}$. DOI: http://dx.doi.org/10.1590/1518-8345.1751.2935. month day year 


\section{Introduction}

Members of the Enterobacteriaceae family are Gram-negative microorganisms found in nature, and isolated from biological material, that colonize the gastrointestinal tract of humans as part of the normal microbiota of this organ system, making it a potential reservoir for these pathogens. Carbapenemresistant Enterobacteriaceae (CRE) have emerged as an important cause of nosocomial infections around the world, and are characterized by rapid, progressive dissemination ${ }^{(1)}$. They are currently an important worldwide public-health problem, as infections due to CRE result in a high mortality rate, with limited therapeutic options ${ }^{(2-3)}$.

Production of $\beta$-lactamase enzymes that can hydrolize carbapenems (carbapenemases) is one of the main mechanisms of resistance in Enterobacteriaceae. According to the existing classification, carbapenemases belong to molecular class A (Klebsiella pneumoniae carbapenemase - KPC), B (metallobetalactamases, of which the primary ones are types VIM, IMP and NDM), and $D$ (the most important being type OXA-48)(4). The $\mathrm{KPC}$ is one of the most epidemiologically important types, because of its worldwide dissemination ${ }^{(5)}$.

Carbapenemases can be transferred between different strains of bacteria, usually by small circular DNA (deoxyribonucleic acid) molecules known as plasmids(4), which can replicate independently from chromosomal DNA, and allow genetic material to be exchanged between different genera and species of Enterobacteriaceae ${ }^{(6)}$. This horizontal transfer of genes can involve multiple pathogens, and become widespread in a hospital setting.

The molecular epidemiology of carbapenemresistant bacteria has been extensively investigated. However, most of the available information comes from studies that investigated specific bacteria(7-10) or specific types of infection ${ }^{(11-12)}$. The risk factors associated with the transmission of resistant pathogens cannot be fully understood when investigations are limited to specific bacteria, because plasmids with resistant traits can be transferred between bacteria of different species. Investigations of infection and colonization by CRE should therefore be more general, and not specify the genus of the bacteria or the patient's clinical condition $^{(1,13-16)}$. Hence, there is a need for a study with a more comprehensive case definition, to provide a better understanding of the risk factors for infection by these microorganisms, so that effective prevention and control measures can be implemented.

The aim of the present exploratory casecontrol study was to identify possible risk factors for acquisition of Enterobacterial strains with a marker for carbapenem resistance.

\section{Method}

\section{Study design}

This case-control study involved patients seen at one public and one not-for-profit hospital (a nongovernmental non-profit facility serving the public health system), each with 300 inpatient beds, in Vitória, ES, Brazil. The hospital infection rates were similar for both hospitals during the study period. The target population was composed of all individuals hospitalized in the two institutions who had suspected nosocomial infection. The sample was composed of individuals with a confirmed presence of CRE by the Medical Microbiology Laboratory of the Central Laboratory Complex (LACEN/ES), between January 1, 2013, and July 31, 2014 (denominated cases). For each case, four randomly selected individuals with laboratory tests negative for CRE or any other organism, who were in the same unit at the same time as the case ( \pm 20 days), composed the matched controls. Individuals whose records contained less than $50 \%$ of the information needed were excluded from the study. Controls whose records had insufficient information were replaced by other randomly selected controls. Approval for the study was granted by the Committee for Ethics in Research at the Center for Health Sciences, Federal University of Espírito Santo (ref. no. 908.781).

\section{Microbiological procedures}

Cultures sent to LACEN/ES were first tested biochemically to investigate bacterial metabolism (Himedia, Mumbai, India) in order to identify the genus/ species of the bacteria isolated. The biochemical tests included glucose, sucrose and lactose fermentation; $\mathrm{CO}_{2}$ production; motility; indole production; urea hydrolysis; lysine, arginine and ornithine decarboxylase activity; citrate and malonate utilization; phenylalanine deaminase activity; and $\mathrm{H}_{2} \mathrm{~S}$ production(17).

Once the bacteria had been identified, samples were tested for antimicrobial susceptibility by disk diffusion on Mueller-Hinton agar (Oxoid, Hampshire, United Kingdom) and Etest (Biomerieux, MarcyI'Étoile, France) to confirm the carbapenem-resistance profile (resistance to ertapenem, imipenem or meropenem), in accordance with standards from the Clinical and Laboratory Standards Institute, (18-19) and modifications in the Brazilian Health Surveillance Agency (Agência Nacional de Vigilância Sanitária - 
ANVISA) technical notes (http://www.anvisa.gov. br). The samples were also screened using the modified Hodge test to detect carbapenemases(18-19), the Etest (Biomerieux, Marcy-l'Étoile, France) to detect extended spectrum betalactamase (ESBL)producing and metallobetalactamase (MBL)-producing bacteria and disk diffusion on Mueller-Hinton agar (Oxoid, Hampshire, United Kingdom), to detect AmpC betalactamase-producing bacteria.

Strains identified as CRE (i.e., strains resistant to ertapenem, imipenem or meropenem) were sent to the Nosocomial Infection Research Laboratory at the Oswaldo Cruz Foundation in Rio de Janeiro (LAPIH/ FIOCRUZ) in tubes with a nutrient agar slant (Himedia, Mumbai, India), for identification of resistant genes by an in-house Polymerase Chain Reaction (PCR) technique to detect the $b / a_{\mathrm{KPC}}$ gene. The Collection of Bacterial Cultures of Hospital (CCBH) Origin 4640 strain (K. pneumoniae ST437 - KPC-2) was used as the positive control, and the American Type Culture Collection (ATCC) 700603 strain (K. pneumoniae ESBL positive) as the negative control. The primers used were KPC-A (5'-CTGTCTTGTCTCTCATGGCC- $\left.3^{\prime}\right)$ and KPC-B ( $5^{\prime}$-CCTCGCTGTGCTTGTCATCC- $\left.3^{\prime}\right)^{(20)}$.

After PCR amplification, the products were processed on $1.5 \%$ agarose gel, and electrophoresis was performed in a Tris, Borato and EDTA (TBE) $0.4 \mathrm{X}$ buffer at room temperature, with a voltage between 80 and $120 \mathrm{~V}$ for approximately 30 minutes. To visualize the amplified products after the run, the gel was stained with ethidium bromide to a final concentration of 0.5 $\mu \mathrm{g} / \mathrm{mL}$ for 17 minutes, and destained in water for 15 minutes. The gel was then visualized under ultraviolet (UV) light and photographed using a Polaroid Gel Doc photodocumentation system. The method used followed the LAPIH/FIOCRUZ protocol.

\section{Variables}

The following items were investigated as possible risk factors: gender; age; hospitalization during the previous 90 days; hospitalization in an intensive care unit; use of a catheter or other invasive device; surgery during the current hospitalization; underlying comorbidities; and antimicrobial agents used during the current hospitalization. Unless otherwise stated, the events and periods considered in the analysis occurred before the biological samples were collected.

\section{Sampling}

To increase the power of the study, four controls hospitalized in the same unit during the same period as the cases were randomly selected and assigned to each case, giving a total of 13 cases and 52 controls enrolled in the study.

\section{Statistical analysis}

Numeric variables were summarized using measures of central tendency and variability. Medians and interquartile ranges were used, as the data did not have a symmetric distribution. Categorical variables were summarized by their absolute frequencies and their proportions in each category.

To investigate the association between the different variables in the data collection instrument and the outcome in question (the presence or absence of CRE), the variables were compared using a univariable logistic regression model. Variables for which the association with the outcome had a p-value of less than 0.2 were included in the multivariable model.

The multivariate analysis was performed using multivariable conditional logistic regression. Effect measures were calculated using the odds ratio, and respective 95\% confidence interval. Goodness-of-fit was assessed by the Hosmer-Lemeshow test ${ }^{(21)}$. The data were analyzed in Statistical Package for the Social Sciences (SPSS), version 17.

\section{Results}

Figure 1 shows the Enterobacteriaceae species isolated in the 13 cases. Table 1 shows demographic and clinical characteristics of cases and controls. Only three of the records selected had to be replaced because of incomplete data. Univariate analysis of the variables, analyzed for their association with the outcome represented by colonization or infection by CRE, showed that length of hospitalization prior to sample collection $(p=0.002)$ and having a surgical procedure $(p=0.006)$ were statistically significant (Table 1 ). All the variables that had a $p$-value of less than 0.2 in the initial stage were included in the logistic regression model (Table 2 ).

\begin{tabular}{|l|l|}
\hline \multicolumn{1}{|c|}{ Enterobacteriaceae } & \multicolumn{1}{c|}{ Sample Type } \\
\hline Klebsiella pneumoniae & Urine (two isolates) \\
\hline Klebsiella pneumoniae & Tracheal aspirate \\
\hline Klebsiella pneumoniae & Blood \\
\hline Enterobacter cloacae & Inguinal swab \\
\hline Enterobacter cloacae & Tissue fragment \\
\hline Enterobacter cloacae & Urine \\
\hline Serratia marcescens & Soft-tissue aspirate \\
\hline Serratia marcescens & Cerebrospinal fluid \\
\hline Serratia marcescens & Urine \\
\hline Serratia marcescens & Wound secretion (two isolates) \\
\hline Serratia marcescens & Blood \\
\hline
\end{tabular}

Figure 1 - Species of Enterobacteriaceae isolated from the 13 cases and the source of each isolate. Vitória, ES, Brazil, 2015 
Table 1 - Univariate analysis of variables potentially associated with colonization and infection by carbapenemresistant Enterobacteriaceae. Vitória, ES, Brazil, 2015

\begin{tabular}{|c|c|c|c|}
\hline Characteristics & Cases $(\mathrm{N}=13)$ & Controls ( $\mathrm{N}=52$ ) & Odds Ratio $\left[95 \% \mathrm{Cl}^{*}\right](\mathrm{p} \text {-value })^{\dagger}$ \\
\hline Gender & & & $0.63[0.18-2.13](0.46)$ \\
\hline Male & $6(46.2 \%)$ & $30(57.7 \%)$ & \\
\hline Female & $7(53.8 \%)$ & $22(42.3 \%)$ & \\
\hline Age & & & $0.99[0.97-1.02](0.74)$ \\
\hline Median & 54.0 years & 65.5 years & \\
\hline Interquartile range & 46.0 to 79.0 years & 46.5 to 78.3 years & \\
\hline Length of hospitalization prior to sample collection & & & $0.92[0.88-0.97](0.002)$ \\
\hline Median & 34 days & 12 days & \\
\hline Interquartile range & 27 to 93.5 days & 5.2 to 21 days & \\
\hline Surgical procedure & & & $9.55[1.91-47.74](0.006)$ \\
\hline Yes & $11(84.6 \%)$ & $19(36.5 \%)$ & \\
\hline No & $2(15.4 \%)$ & $33(63.5 \%)$ & \\
\hline Previous hospitalization (90 days) & & & $0.86[0.25-2.90](0.80)$ \\
\hline Yes & $6(46.2 \%)$ & $26(50 \%)$ & \\
\hline No & $7(53.8 \%)$ & $26(50 \%)$ & \\
\hline Hospitalization in intensive care unit & & & $4.36[0.88-21.67](0.07)$ \\
\hline Yes & $11(84.6 \%)$ & $29(55.8 \%)$ & \\
\hline No & $2(15.4 \%)$ & $23(44.2 \%)$ & \\
\hline Use of catheters and/or invasive devices & & & $3.09[0.76-12.52](0.12)$ \\
\hline Yes & $10(76.9 \%)$ & $27(51.9 \%)$ & \\
\hline No & $3(23.1 \%)$ & $25(48.1 \%)$ & \\
\hline Comorbidities $^{\ddagger}$ & & & $1.65[0.32-8.50](0.55)$ \\
\hline Yes & $11(84.6 \%)$ & $40(76.9 \%)$ & \\
\hline No & $2(15.4 \%)$ & $12(23.1 \%)$ & \\
\hline Use of antibiotics & & & $4.00[0.47-33.81](0.20)$ \\
\hline Yes & $12(92.3 \%)$ & $39(75 \%)$ & \\
\hline No & $1(7.7 \%)$ & $13(25 \%)$ & \\
\hline Total & 13 & 52 & - \\
\hline
\end{tabular}

*CI: Confidence Interval

tUnivariable logistic regression model.

₹ Most frequently detected comorbidities: arterial hypertension (35.4\%), diabetes mellitus (24.6\%), heart disease (13.8\%), HIV infection (12.3\%), cancer $(7.7 \%)$ and stroke $(4.6 \%)$.

Both variables remained significant in the multivariable logistic regression. Length of hospitalization prior to sample collection had an odds ratio of 0.93 ( $p$ $=0.009 ; 95 \% \mathrm{CI}: 0.89$ to 0.98$)$, and surgical procedure had an odds ratio of 9.28 ( $p=0.05$; CI $95 \%=1.01$ to $85.14)$. In other words, there was a $6.6 \%$ reduction per day of hospitalization avoided in the risk of CRE being isolated. The measure of effect for surgical procedure revealed a nine times greater possible risk of having samples positive for CRE for patients who underwent these procedures, with a very large confidence interval. This large interval indicates that the estimates from the logistic model are probably unstable, due to the small number of non-surgical cases (only two out of thirteen).

Of the $13 \mathrm{CRE}$ isolates tested for resistance genes using PCR, nine $(69.2 \%)$ were positive for the $b_{\text {bPC }}$ gene: four isolates of $K$. pneumoniae, three of Enterobacter cloacae and two of Serratia marcescens.
Table 2 - Multivariate analysis of risk factors for colonization and infection by carbapenem-resistant Enterobacteriaceae. Vitória, ES, Brazil, 2015

\begin{tabular}{lc}
\hline \multicolumn{1}{c}{ Characteristics } & Odds Ratio $\left[95 \% \mathrm{Cl}^{*}\right]$ ( $p$-value $)$ \\
\hline Length of hospitalization prior to & $0.93[0.89-0.98]$ \\
sample collection & $(p=0.009)$ \\
Hospitalization in intensive care & $1.69[0.09-31.62]$ \\
unit & $(p=0.72)$ \\
Use of catheter and/or invasive & $1.68[0.13-22.19]$ \\
device & $(p=0.69)$ \\
Surgical procedure & $9.28[1.01-85.14]$ \\
& $(p=0.05)$ \\
\hline
\end{tabular}

*Confidence interval.

\section{Discussion}

Our findings show that there was a statistically significant association between isolation of CRE and either length of hospitalization prior to sample collection, or surgical procedure. This association remained 
significant in the multivariable logistic regression model. Patients who were positive for CRE had a 34-day median length of hospitalization prior to sample collection. This agrees with studies in which the length of hospitalization prior to sample collection is reported to vary from two to four weeks ${ }^{(22-23)}$. This finding can be used to characterize CRE infection as a late-onset nosocomial complication.

Having surgery was a risk factor for acquiring CRE. This finding is in agreement with a previous study that described surgery as being more common in patients with CRE infection, and corroborates the finding that medical procedures play a significant role in increased susceptibility of hospitalized patients to certain infections ${ }^{(24)}$.

Some of the cases in this study were infected with isolates of CRE that carried the bla $a_{\mathrm{KPC}}$ gene, and others were infected with isolates that did not. The decision to include both types of case was taken to allow a broader case definition, to help identify associations between different factors and the presence of multiresistant bacteria, and thereby prevent their dissemination, which is of prime importance in nosocomial epidemiology.

However, the study had several limitations. Because it was retrospective, some important information was missing from the hospital database, and could not therefore be used in the analysis. This may have introduced selection or information bias. The variability of the quantitative data reflects the limited precision resulting from the small number of observations, and indicates limited statistical power, which in turn can mean that valid associations may not have been identified. The large intervals also reveal some instability of the estimates of the coefficients in the model, preventing precise estimation of the strength of the associations. Control patients were randomly selected without a strictly established criterion for matching, which is suitable for an exploratory case-control study, but can lead to confounding. Nevertheless, confounding was probably reduced because only controls that had been in the same hospital unit at the same time as the cases were selected. Furthermore, because of its retrospective nature, as the data were obtained from medical records and not directly from the patients, the study did not provide information about possible previous colonization of control patients by CRE.

\section{Conclusion}

This study investigated risk factors associated with CRE colonization or infection in different inpatient units in two hospitals. The findings show that, independent of the Enterobacteriacea isolated, the type of infection, or the inpatient unit, length of hospitalization and having a surgical procedure increase the probability of acquiring CRE.

These results highlight the importance of taking effective preventive measures to avoid the spread of CRE in hospital settings. This is particularly important for health professionals, as they have free access to the inpatient units in a hospital and are in direct contact with hospitalized patients. Therefore, correct cleaning and disinfection procedures complying with regulatory agency guidelines should be followed.

The high potential for spreading CRE in a hospital setting makes effective preventive measures essential. Knowledge of the risk factors associated with acquisition of CRE, and implementation of preventive measures, such as decreasing hospitalization times and increasing surveillance of surgical patients, could play a decisive role in reducing the spread of these microorganisms in hospital settings.

\section{Acknowledgments}

To Laboratório Central de Saúde Pública (LACEN Espírito Santo) and Laboratório de Pesquisa em Infecção Hospitalar (LAPIH) - Fundação Oswaldo Cruz (FIOCRUZ) for providing the data, and to the Hospital Estadual Central and Hospital Santa Casa de Misericórdia in Espírito Santo for authorizing the data collection.

\section{References}

1. Torres-Gonzalez P, Cervera-Hernandez ME, NiembroOrtega MD, Leal-Vega F, Cruz-Hervert LP, GarcíaGarcía $L$, et al. Factors associated to prevalence and incidence of carbapenem-resistant Enterobacteriaceae Fecal carriage: a cohort study in a Mexican Tertiary Care Hospital. PLoS One. [Internet]. 2015 [cited Jan 2, 2016]; 10(10):1-13. Available from: http://www.ncbi. nlm.nih.gov/pubmed/26431402. doi:10.1371/journal. pone.0139883

2. Morrill HJ, Pogue JM, Kaye KS, LaPlante KL. Treatment options for carbapenem resistant Enterobacteriaceae infections. Open Forum Infect Dis. [Internet]. 2015 [cited Jan 30, 2017]; 2(2):1-15. Available from: https:// www.ncbi.nlm.nih.gov/pmc/articles/PMC4462593. doi: 10.1093/ofid/ofv050

3. Satlin MJ, Jenkins SG, Walsh TJ. The global challenge of carbapenem-resistant Enterobacteriaceae in transplant recipients and patients with hematologic malignancies. Clin Infect Dis. [Internet]. 2014 [cited Jan 30, 2017]; 58(9):1274-83. Available from: https://www.ncbi.nlm. nih.gov/pmc/articles/PMC4038783. doi: 10.1093/cid/ ciu052 
4. Del Franco M, Paone L, Novati R, Giacomazzi CG, Bagattini M, Galotto C, et al. Molecular epidemiology of carbapenem resistant Enterobacteriaceae in Valle d'Aosta region, Italy, shows the emergence of KPC- 2 producing Klebsiella pneumoniae clonal complex 101 (ST101 and ST1789). BMC Microbiol. [Internet]. 2015 [cited Jan 2, 2016]; 15(1):1-9. Available from: http://www.ncbi.nlm. nih.gov/pubmed/26552763. doi: 10.1186/s12866-0150597-z.

5. Doi Y, Paterson DL. Carbapenemase-producing Enterobacteriaceae. Semin Respir Crit Care Med. [Internet]. 2015[cited Jan 30, 2017]; 36(1):74-84. Available from: https://www.ncbi.nlm.nih.gov/pmc/ articles/PMC4470611. doi:10.1055/s-0035-1544208

6. Adamczuk M, Zaleski P, Dziewit L, Wolinowska R, Nieckarz $M$, Wawrzyniak $P$, et al. Diversity and global distribution of IncL/M plasmids enabling horizontal dissemination of $\beta$-Lactam resistance genes among the Enterobacteriaceae. Biomed Res Int. [Internet]. 2015[cited Jan 31, 2017]; Article ID 414681, 12 pages. Available from: https://www.ncbi.nlm.nih.gov/pmc/ articles/PMC4510254. doi: 10.1155/2015/414681.

7. da Silva KE, Maciel WG, Sacchi FP, Carvalhaes CG, Rodrigues-Costa $F$, da Silva $A C$, et al. Risk factors for KPC-producing Klebsiella pneumoniae: watch out for surgery. ] Med Microbiol .[Internet]. 2016. [cited Jan 6, 2017]; 65(6):547-53. Available from: https://www. ncbi.nlm.nih.gov/pubmed/27002853. doi: 10.1099/ jmm.0.000254.

8. Gómez Rueda V, Zuleta Tobón JJ. Risk factors for infection with carbapenem-resistant Klebsiella pneumoniae: a case-case-control study. Colomb Med. (Cali). [Internet]. 2014 [cited Dec 29, 2015]; 45(2):5460. Available from: http://www.ncbi.nlm.nih.gov/ pubmed/25100889.

9. Akturk $H$, Sutcu $M$, Somer A, Aydın D, Cihan R, Ozdemir A, et al. Carbapenem-resistant Klebsiella pneumoniae colonization in pediatric and neonatal intensive care units: risk factors for progression to infection. Braz J Infect Dis. [Internet]. 2016. [cited April 17, 2017]; 20(2):134-40. Available from: https://www. ncbi.nlm.nih.gov/pubmed/26867474. doi: 10.1016/j. bjid.2015.12.004

10. Candevir Ulu A, Kurtaran B, Inal AS, Kömür S, Kibar F, Yapıcı Çiçekdemir $H$, et al. Risk factors of carbapenem resistant Klebsiella pneumoniae infection: a serious threat in ICUs. Med Sci Monit. [Internet] 2015 [cited Jan 31, 2017]; 21:219-24.Available from: https:// www.ncbi.nlm.nih.gov/pmc/articles/PMC4304439. doi: 10.12659/MSM.892516

11. Eshetie S, Unakal C, Gelaw A, Ayelign B, Endris M, Moges F. Multidrug resistant and carbapenemase producing Enterobacteriaceae among patients with urinary tract infection at referral Hospital, Northwest Ethiopia. Antimicrob Resist Infect Control. [Internet]. 2015 [cited Jan 3, 2016]; 4:1-8. Available from: http://www.ncbi.nlm.nih.gov/pubmed/25908966. doi: 10.1186/s13756-015-0054-7.

12. Ivády B, Kenesei É, Tóth-Heyn P, Kertész G, Tárkányi $\mathrm{K}$, Kassa $\mathrm{C}$, et al. Factors influencing antimicrobial resistance and outcome of Gram negative bloodstream infections in children. Infection. [Internet]. 2015 [cited Jan 4, 2016]; 43:1-13. Available from: http://www. ncbi.nlm.nih.gov/pubmed/26546372. doi: 10.1007/ s15010-015-0857-8.

13. Ling $M L$, Tee $Y M$, Tan SG, Amin IM, How KB, Tan $K Y$, et al. Risk factors for acquisition of carbapenem resistant Enterobacteriaceae in an acute tertiary care hospital in Singapore. Antimicrob Resist Infect Control. [Internet]. 2015 [cited Jan 4, 2016]; 4(26):17. Available from: http://www.ncbi.nlm.nih.gov/pmc/ articles/PMC4477303. doi: 10.1186/s13756-015-00663.

14. Norcia BMM, Capobiango JD, Vespero EC, Pelisson M. Pacientes pediátricos portadores de enterobactéria resistente aos carbapenêmicos em um hospital escola do Sul do Brasil. J Infect Control. [Internet]. 2015 [cited Jan 4, 2016]; 4(1): 11-5. Available from: http://jic.abih. net.br/index.php/jic/article/view/95/pdf.

15. Miller BM, Johnson SW. Demographic and infection characteristics of patients with carbapenemresistant Enterobacteriaceae in a community hospital: development of a bedside clinical score for risk assessment. Am J Infect Control. [Internet]. 2016 [cited May 5, 2016]; 44(2):134-7. Available from: http://www. ncbi.nlm.nih.gov/pubmed/26492818. doi: 10.1016/j. ajic.2015.09.006

16. Fitzpatrick M, Zembower T, Malczynski M, Qi C, Bolon MK. Outcomes of an enhanced surveillance program for carbapenem-iesistant Enterobacteriaceae. Infect Control Hosp Epidemiol. [Internet]. 2014 [cited Jan 6, 2016]; 35(4): 419-22. Available from: http://www.ncbi.nlm. nih.gov/pubmed/24602948. doi: 10.1086/675595.

17. Rutherford I, Moody V, Gavan TL, Ayers LW, Taylor DL. Comparative study of three methods of identification of Enterobacteriaceae. J Clin Microbiol. [Internet]. 1977. [cited Jan 6, 2017]; 5(4):458-64. Available from: https://www.ncbi.nlm.nih.gov/pubmed/323287.

18. CLSI. Performance standards for antimicrobial susceptibility testing. Wayne, Pennsylvania. Clin Lab Stand Inst. [Internet]. 2011 [cited Sep 20, 2015]. Available from: http://www.readbag.com/rsu-ac-thmedtech-files-clsi-2011.

19. CLSI. Performance Standards for Antimicrobial Susceptibility Testing.Wayne, Pennsylvania. Clin Lab Stand Inst. [Internet]. 2012 [cited Sep 20, 2015]. 2012. 
Available from: http://www.anvisa.gov.br/servicosaude/ manuais/clsi.asp.

20. Naas T, Cuzon G, Villegas MV, Lartigue MF, Quinn JP, Nordmann P. Genetic structures at the origin of acquisition of the beta-Lactamase blaKPC gene. Antimicrob Agents Chemother. [Internet]. 2008 [cited Jan 16, 2016]; 52 (4):1257-63. Available from: http://www.ncbi.nlm.nih. gov/pubmed/18227185. doi: 10.1128/AAC.01451-07.

21. Hosmer DW, Lemeshow S, Sturdivant RX. Applied Logistic Regression. 3rd. ed. New York: Wiley; 2013. $528 \mathrm{p}$.

22. Yang J, Yanghua Q, Jiajun L, Qiang L, Yuchao D, Yan S, et.al. Risk factors for carbapenem-resistant Klebsiella pneumoniae infection/colonization and predictors of mortality: a retrospective study. Pathog Glob Health. [Internet] 2015 [cited Jan 31, 2017]; 109(2): 68-74. Available from: https://www. ncbi.nlm.nih.gov/pmc/articles/PMC4455340.doi: 10.1179/2047773215Y.0000000004

23. Paño-Pardo JR, Serrano Villar S, Ramos Ramos JC, Pintado V. Infections caused by carbapenemase-producing Enterobacteriaceae: risk factors, clinical features and prognosis. Enferm Infecc Microbiol Clin. [Internet ]. 2014 [cited Jan 31, 2017]; 32 (4):41-8. Available from: http://www.ncbi.nlm.nih.gov/pubmed/25542051. doi:10.1016/S0213-005X(14)70173-9.

24. Xiujuan $M$, Sidi $L$, Juping $D$, Xun $H$, Pengcheng $Z$, Xinrui $X$, et al. Risk factors and medical costs for healthcare-associated carbapenem-resistant Escherichia coli infection among hospitalized patients in a Chinese teaching hospital. BMC Infect Dis. [Internet] 2017 [cited Feb 1, 2017]; 17:82. Available from: https://www.ncbi. nlm.nih.gov/pmc/articles/PMC5242049. doi: 10.1186/ s12879-016-2176-9.

Corresponding Author:

Crispim Cerutti Junior

Universidade Federal do Espírito Santo

Av. Marechal Campos, 1468

Bairro: Maruípe

CEP: 29043-900, Vitória, ES, Brasil

E-mail: fil.cris@terra.com.br
Copyright $\odot 2017$ Revista Latino-Americana de Enfermagem This is an Open Access article distributed under the terms of the Creative Commons (CC BY).

This license lets others distribute, remix, tweak, and build upon your work, even commercially, as long as they credit you for the original creation. This is the most accommodating of licenses offered. Recommended for maximum dissemination and use of licensed materials. 